\title{
FORMULA OPTIMIZATION AND IN VITRO RELEASE KINETIC STUDIES OF DILTIAZEM HYDROCHLORIDE MUCOADHESIVE BILAYER BUCCAL FILM
}

\section{LINA WINARTI ${ }^{*}$, AFALAH ZULFA LAILY ${ }^{1}$, LUSIA OKTORA RUMA KUMALA SARI ${ }^{1}$, EKA DEDDY IRAWAN ${ }^{1}$, DWI NURRAHMANTO ${ }^{1}$, VIDDY AGUSTIAN ROSYIDI', KUNI ZUAIMAH BARIKAH ${ }^{1}$, LIDYA AMELIANA ${ }^{1}$}

\author{
1Department of Pharmaceutics, Faculty of Pharmacy, University of Jember, Jember, 68121, Indonesia
}

*Email: lina.winarti@unej.ac.id

Received: 01 Sep 2020, Revised and Accepted: 08 Oct 2020

\section{ABSTRACT}

Objective: This research aims to determine the amount of hydroxypropyl methylcellulose (HPMC) and chitosan, which can produce the optimum buccal film formula and to determine the release kinetics of diltiazem hydrochloride in vitro.

Methods: The film was prepared by the solvent casting method. The formula's optimization was carried out using factorial design, which was processed using Design Expert 11.0.0 software, while the release kinetics was analyzed using the DDSolver program.

Results: The optimization results show that HPMC and chitosan (30 mg: $10 \mathrm{mg}$ ) is the amount of polymer that can produce the optimum formula. The buccal film formula has a swelling index of 2.92, a mucoadhesive strength of $64.40 \mathrm{gF}$, and a mucoadhesive residence time of 464 min. In vitro release study showed $97.64 \%$ release of Diltiazem hydrochloride after $480 \mathrm{~min}$. The release kinetic's of diltiazem hydrochloride follow the Korsmeyer Peppas model.

Conclusion: Thus, it can be concluded that the prepared formulation of the buccal mucoadhesive film can be a delivery system for diltiazem hydrochloride.

Keywords: Mucoadhesive bilayer buccal film, Diltiazem hydrochloride, HPMC, Chitosan, Factorial design

(C) 2021 The Authors. Published by Innovare Academic Sciences Pvt Ltd. This is an open access article under the CC BY license (http://creativecommons.org/licenses/by/4.0/) DOI: http://dx.doi.org/10.22159/ijap.2021.v13s2.02 Journal homepage: https://innovareacademics.in/journals/index.php/ijap

\section{INTRODUCTION}

Hypertension is a persistent increase in systolic and diastolic blood pressure more than $140 \mathrm{mmHg}$ and $90 \mathrm{mmHg}$. Diltiazem hydrochloride can reduce Hypertension [1]. In vivo, diltiazem hydrochloride has $40 \%$ bioavailability due to first-pass metabolism [2]. The buccal delivery system is suitable as an alternative for diltiazem hydrochloride drug delivery because it could avoid the first-pass metabolism.

Buccal preparations include patch, tablet, semisolid, powder, and film [3]. The buccal film is thinner, smaller in size, minimal side effects, and flexible $[4,5]$. The bilayered buccal film consists of an insoluble backing layer and a mucoadhesive layer containing drugs. The backing layer uses to regulate the drug release in one direction so that it prevents the drug from dissolving in saliva, prevents loss of the drug from the top, and can mask the drug's bitter taste [6]. The mucoadhesive layer uses to prolong drug contact with mucus [7].

In this study, the solvent casting method uses to prepare the buccal film. The type and amount of polymer used for the buccal film will influence the characteristics, kinetics, and drug release mechanism from buccal film preparation. Therefore, in this research, we will optimize HPMC and chitosan composition using a factorial design. HPMC and chitosan are polymers that can expand and form polymer chains if attached to the mucosa $[8,9]$. HPMC is a polymer with good film-forming properties, transparent and better mucoadhesive properties $[10,11]$. Chitosan is a natural polysaccharide from chitin deacetylation that is non-toxic, biodegradable, and biocompatible [12]. Chitosan also has good mucoadhesive properties [13]. The combination of these two polymers could increase the mucoadhesive strength and film residence time.

Dissolution is critical for absorption and bioavailability; therefore, information on the release mechanism and kinetics is essential to evaluate. The DD Solver program is simple and easy to use for data dissolution modeling [14]. DD Solver is a program developed to analyze dissolution data kinetics [15] with a non-linear regression approach. Hence, the model and mechanism of dissolution of Diltiazem hydrochloride mucoadhesive buccal film were evaluated with the help of DD Solver program.

\section{MATERIALS AND METHODS}

\section{Chemical and reagent}

Materials used in this study were Diltiazem hydrochloride from PT. Kimia Farma (Jakarta, Indonesia). Chitosan (94\% deacetylation degree) was obtained from CV. Chimultiguna (Cirebon, Indonesia). HPMC K4M, glycerin, acetone, $\mathrm{KH}_{2} \mathrm{PO}_{4}, \mathrm{HCl}$, and $\mathrm{NaOH}$ were purchased from PT. BrataChem (Jakarta, Indonesia). Ethylcellulose N-100 was purchased from Asian Chemical (Jakarta, Indonesia). Goat buccal mucosa of 3-4 y old was obtained from local slaughterhouses.

\section{Animal experimental}

The use of animals follows the protocol approved by the Ethics Committee of Medical Research Faculty of Dentistry Universitas Jember no. 895/UN25.8/KEPK/DL/2020.

\section{Instrument}

The instruments used in this study were the TA. XT2 plus Texture Analyzer (UK), Alpha Bruker FT-IR Spectroscopy (UK), USP paddletype dissolution test equipment (Logan, Germany), $\mathrm{pH}$ meter (Elmetron CP-502, Poland), UV Vis Spectrophotometer (Genesys 10S, Thermo Scientific, USA), analytical balance (Adventurer TM Ohaus, USA), oven (Memmert, Germany), screw micrometer, DesignExpert software version 11.0.0, DD Solver program, desiccator (Normax), and glass tools.

\section{Experimental design}

Formulas preparation uses a factorial design of two-factor and twolevel. The amount of polymer used is set at a low level and high level. The low level of HPMC is $15 \mathrm{mg}$, while the high level is 30 $\mathrm{mg}$. The low level of chitosan is $5 \mathrm{mg}$, while the high level is $10 \mathrm{mg}$.

\section{Buccal film preparation}

The film formula (table 1) caste on a $9 \mathrm{~cm}$ diameter petri dish. The film cuts into $2 \times 2 \mathrm{~cm}$. Each contains $40 \mathrm{mg}$ of Diltiazem hydrochloride. Diltiazem hydrochloride and HPMC dissolve in water while chitosan dissolves in $1 \%$ acetic acid. The solutions mix added 
with glycerin then stirred until homogeneous. The dissolved component is poured into a mold and allowed to stand for $24 \mathrm{~h}$ to remove air bubbles. The mixture was dried in an oven at $50^{\circ} \mathrm{C}$ for 24 h. The backing layer, ethylcellulose in acetone, pours on the film's surface containing Diltiazem hydrochloride. The next step is drying in an oven at $70{ }^{\circ} \mathrm{C}$ for $60 \mathrm{~min}$ [15].

Table 1: The formula composition of mucoadhesive bilayer buccal film diltiazem hydrochloride

\begin{tabular}{lllll}
\hline Materials & Function & Formula code & & \\
\cline { 2 - 4 } & & F1 & FA & FB \\
\hline Diltiazem hydrochloride & Active ingredient & $0.60 \mathrm{~g}$ & $0.60 \mathrm{~g}$ & $0.60 \mathrm{~g}$ \\
HPMC & Film forming & $0.24 \mathrm{~g}$ & $0.48 \mathrm{~g}$ & $0.24 \mathrm{~g}$ \\
Chitosan & Mucoadhesive & $0.08 \mathrm{~g}$ & $0.08 \mathrm{~g}$ & $0.16 \mathrm{~g}$ \\
Ethylcellulose & Backing layer & $0.23 \mathrm{~g}$ & $0.48 \mathrm{~g}$ \\
Aceton & Solvent & $22.5 \mathrm{ml}$ & $0.16 \mathrm{~g}$ \\
Glycerin & Plasticizer & $0.5 \mathrm{ml}$ & $0.23 \mathrm{~g}$ & $22.5 \mathrm{ml} \mathrm{ml}$ \\
Acetic acid & Solvent & $3 \mathrm{ml}$ & $0.5 \mathrm{ml}$ & $0.5 \mathrm{ml}$ \\
Distilled water & Solvent & $7 \mathrm{ml}$ & $3 \mathrm{ml}$ & $7.5 \mathrm{ml}$ \\
\hline
\end{tabular}

\section{The evaluation of Physico-chemical of prepared buccal films}

The organoleptic study was performed visually by observing the color, taste, smell, and film texture. The film thickness was measured by using a screw micrometer. The Films are measured at five different positions. The measurement results state as the mean and standard deviation $[16,17]$. The film weight was determined by weighing, and the result presented as mean and standard deviation [18]

The film's endurance was evaluated by repeated folding the film 300 times in the same place until it breaks $[16,19]$.

Surface $\mathrm{pH}$ was determined by soaked the film in $1 \mathrm{ml} \mathrm{of} \mathrm{pH} 6.8$ phosphate buffer for $2 \mathrm{~h}$ at room temperature; then, the surface $\mathrm{pH}$ is measured using electrodes [16].

Determination of diltiazem hydrochloride content in a buccal film was carried out by dissolving a film containing $40 \mathrm{mg}$ of Diltiazem hydrochloride in a phosphate buffer (pH 6.8). Diltiazem hydrochloride measures using a UV spectrophotometer at maximum wavelength [20]. Diltiazem hydrochloride content calculates by equation (1).

$\%$ content of the active ingredient $=\frac{\text { content of drug in the film }}{\text { amount of drug added }} \times 100 \%$ (1)

\section{Swelling index}

The films (W0) was weighing to determine the initial weight and then put in a petri dish containing $5 \mathrm{ml}$ of phosphate buffer $(\mathrm{pH}$ 6.8) and allowed to swell $(\mathrm{Wt})[16,21]$. The swelling index calculated using equation (2).

$$
\text { Swelling index }=\frac{\mathrm{Wt}-\mathrm{W} 0}{\mathrm{~W} 0}(2)
$$

Description:

$\mathrm{W} 0=$ initial weight of the film

$\mathrm{Wt}=$ final weight after time interval $\mathrm{t}$

\section{Mucoadhesive strength}

The test was conducted using the goat's buccal mucosa by given a force of $500 \mathrm{gF}$ on a texture analyzer that was run by XTRA Dimension Software. The mucoadhesive strength states with units of gram force (gF) [22].

\section{Mucoadhesive residence time}

The test performs on a buccal film by attached the film to the buccal mucosa for $30 \mathrm{~s}$. The buccal mucosa is attached to the center of the slide. The slide soaked in $500 \mathrm{ml}$ of phosphate buffer ( $\mathrm{pH} \mathrm{6.8)} \mathrm{at}$ $37 \pm 0.5^{\circ} \mathrm{C}$, and stirred at $500 \mathrm{rpm}$ for $8 \mathrm{~h}$. The residence time is determined when the film begins to detach [23].

\section{Fourier transform infrared (FTIR)}

FTIR test was performed to confirm the interaction between Diltiazem hydrochloride and film components, which could retard diltiazem hydrochloride release from the buccal film or reduce its effectiveness. Scanning did in the wavenumber of 4000-600 $\mathrm{cm}^{-1}$.

\section{Scanning electron microscopy (SEM)}

SEM analysis was performed by placing a film on a stub specimen attached to a conductive tape. The film was then placed on a specimen holder with a $15 \mathrm{kV}$ voltage and a pressure of $0.1 \mathrm{mmHg}$. The top, bottom, and cross-section of the film are captured with 40 , 100,300 magnifications.

\section{Analysis of data}

Each buccal film's dependent variables were processed using Design expert 11.0.0 to obtain the optimum formula. The release study analyzed using DD Solver program to determine the release kinetics model and mechanism.

\section{RESULTS AND DISCUSSION}

\section{Physico-chemical evaluation of prepared buccal films}

Diltiazem hydrochloride mucoadhesive bilayer buccal films formula of F1, FA, FB, and FAB are yellow, odorless, slightly sweet, elastic, and smooth. The result of the buccal film Physico-chemical evaluation is presented in table 2 .

The buccal film's thickness meets the ideal film criteria between 50 $1000 \mu \mathrm{m}$ [24]. The Film thickness and weight uniformity relate to dose uniformity. Both parameters show uniformity, as indicated by small SD values. The film thickness and weight influence by the number of polymers of each different formula.

The folding endurance test of each formula shows that the films resist to more than 300 times fold. These results indicate that the film is not easily damaged due to movement and mechanical friction in the oral environment [19].

The surface $\mathrm{pH}$ meets the buccal $\mathrm{pH}$ requirements of 5.5-7 [23]; therefore, they do not irritate the mucosa and cause discomfort during use. The buccal film's Diltiazem hydrochloride content showed that it fulfilled $85-115 \%$ [25], which is indicates that only small drug loss during formulation. The coefficient of variation (CV) meets the $\mathrm{CV}$ requirements, which is less than $6 \%$ [26].

\section{Measurements of swelling index}

The swelling index shows that $\mathrm{FA}>\mathrm{FAB}>\mathrm{FB}>\mathrm{F} 1$ (table 2). FA uses a high number of HPMC and low number of chitosan. In a larger number, the FA uses HPMC to give a better swelling index due to the hydrophilic groups resulting in greater hydration [27]. In contrast with HPMC, chitosan is slightly soluble in water and only dissolves in acidic conditions, resulting in low hydration.

\section{Mucoadhesive strength}

The mucoadhesive strength shows that $\mathrm{FAB}>\mathrm{FA}>\mathrm{FB}>\mathrm{F} 1$ (table 2). The FAB formula had a high level of HPMC and chitosan. The amount of polymer used can affect the amount of mucoadhesive strength. Less polymer number can reduce the number of chains per unit that will penetrate to the mucus. Besides, it can reduce the interaction between polymer and mucus; hence the bonds are unstable, while large polymer numbers can increase the chain penetration and adhesive properties. 
HPMC has moderate mucoadhesive properties. In large quantities, HPMC can increase mucoadhesive strength [28]. The hydroxyl groups in HPMC bind to the mucosa to form hydrogen bonds and produce good properties of mucoadhesive [29]. Chitosan is a cationic polymer that can bind with the sialic acid groups in mucin; therefore, a large amount of chitosan increases the mucoadhesive strength [28].

Table 2: The results of buccal film evaluation

\begin{tabular}{llll}
\hline Evaluation parameters & F1 & FA & FB \\
\hline Thickness $^{*}(\mathrm{~cm})$ & $0.02 \pm 0.00$ & $0.03 \pm 0.00$ & $0.02 \pm 0.00$ \\
Weight $\left.^{*} \mathrm{mg}\right)$ & $76.10 \pm 0.45$ & $98.70 \pm 0.27$ & $84.90 \pm 0.27$ \\
Folding endurance $^{*}$ & $>300 \mathrm{x}$ & $>300 \mathrm{x}$ & $>300 \mathrm{x}$ \\
Surface pH $^{*}$ & $6.26 \pm 0.04$ & $6.46 \pm 0.04$ & $6.11 \pm 0.02$ \\
Drug content $^{*}(\%)$ & $96.87 \pm 0.83$ & $96.17 \pm 1.42$ & $95.85 \pm 0.61$ \\
Swelling Index $^{*}$ & $2.35 \pm 0.02$ & $3.28 \pm 0.01$ & $2.68 \pm 0.04$ \\
Mucoadhesive strength $^{*}(\mathrm{gF})$ & $37.90 \pm 0.20$ & $53.73 \pm 1.80$ & $48.17 \pm 1.63$ \\
Residence time $^{*}(\mathrm{~min})$ & $375.33 \pm 2.08$ & $444.67 \pm 4.04$ & $405.33 \pm 3.06$ \\
\hline
\end{tabular}

Note: Ratio of HPMC to chitosan of F1 (15: 5); FA (30: 5); FB (15:10); FAB (30:10). Values are expressed as mean \pm SD, n=3

\section{Mucoadhesive residence time}

The mucoadhesive residence time showed that $\mathrm{FAB}>\mathrm{FA}>\mathrm{FB}>\mathrm{F} 1$. The mucoadhesive residence time relates to the length of the buccal film stays at mucosa [10]. These results indicate that a combination of two polymers, HPMC and chitosan, could increase mucoadhesive strength and residence time in the mucosa. This result is in accordance with [9] studies using polymer combination of HPMC$4 \mathrm{KM}$ with chitosan for Sodium Risedronate could increase the mucoadhesive strength and mucoadhesive residence time.

\section{Formula optimization}

The independent variables in this research were HPMC (X1) dan chitosan (X2), while the dependent variables were a swelling index (Y1), a mucoadhesive strength (Y2), and a mucoadhesive residence time (Y3). The swelling index, mucoadhesive strength, and
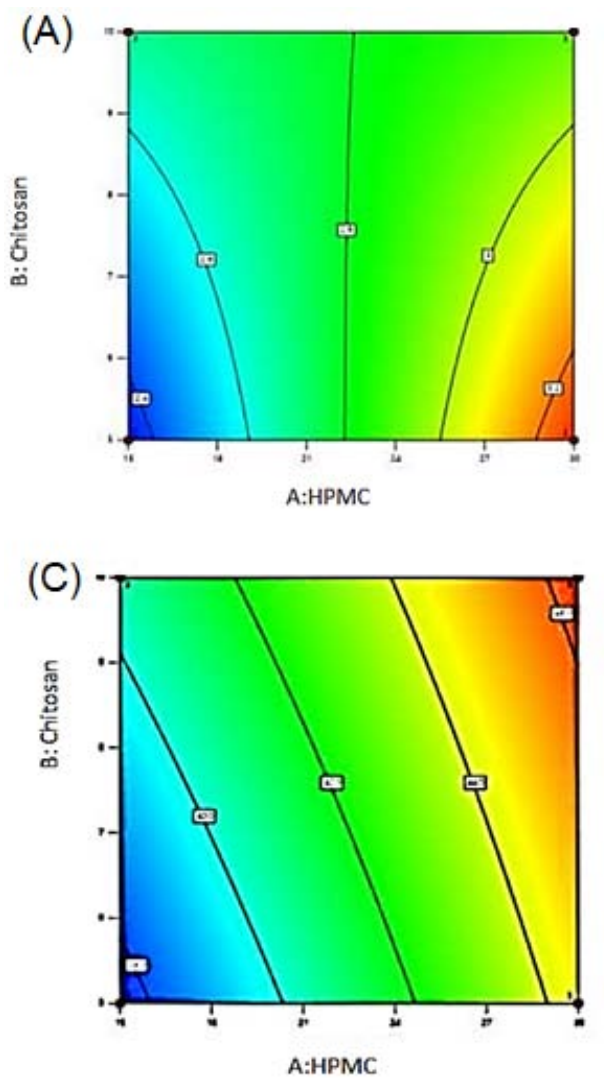

mucoadhesive residence time were analyzed using the software of design expert version 11.0.0 to obtain the following equation (3), (4), (5):

Swelling index $(\mathrm{Y} 1)=2.81+0.2931 * \mathrm{X} 1-0.0074 * \mathrm{~B}-0.1737 * \mathrm{X} 1 \mathrm{X} 2(3)$

Mucoadhesive strength $(\mathrm{Y} 2)=51.05+8.02+5.23 * \mathrm{X} 1 * \mathrm{X} 2+0.100 *$

$$
\mathrm{X} 1 \mathrm{X} 2(4)
$$

Mucoadhesive residence time $(\mathrm{Y} 3)=422.33+32.00 * \mathrm{X} 1+12.33 * \mathrm{X} 2$ -

$$
2.67 * \mathrm{X} 1 \mathrm{X} 2(5)
$$

Where X1 = amount of HPMC; X2 = amount of chitosan.

The contour plot of a swelling index response, mucoadhesive strength, and mucoadhesive residence time is shown in fig. 1 . The red color in the contour plot shows the highest predicted response, while the blue color indicates the lowest predicted response.
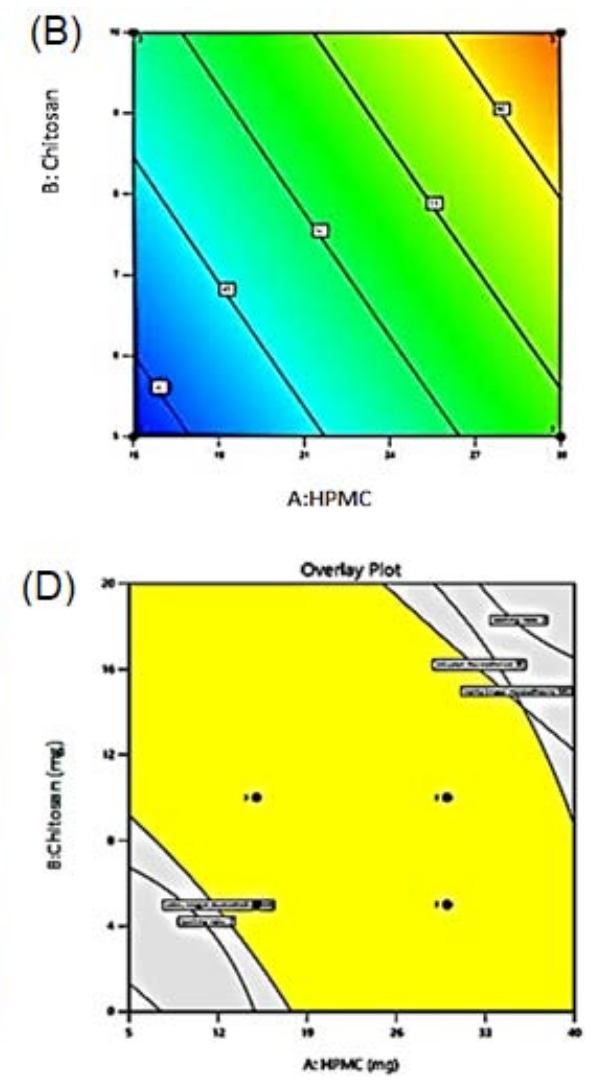

Fig. 1: The Contour plots of a swelling index (A), a mucoadhesive strength (B), a mucoadhesive residence time (C), and an overlay plot of the optimum area (D) 
The optimum area is a result of an overlay plot of a swelling index, a mucoadhesive strength, and mucoadhesive residence time (fig. 1). The optimized area produced from the overlay of the three responses is shown in yellow color, which indicates the amount of HPMC and chitosan that meet the desired criteria. FAB is the optimum formula with the desirability index of 0.80 containing HPMC and chitosan $30 \mathrm{mg}: 10 \mathrm{mg}$.

\section{FTIR analysis}

FTIR spectra of Diltiazem hydrochloride in red color and Diltiazem hydrochloride mucoadhesive bilayer buccal film in blue color (fig. 2). FTIR spectra of diltiazem hydrochloride and diltiazem hydrochloride mucoadhesive bilayer buccal film shows the spectra met the characteristic range of diltiazem hydrochloride (fig. 2). There was no sharp band shift and significant changes in wavelength. Diltiazem hydrochloride contains an active metabolite, desacetyl diltiazem, that provides a therapeutic effect [2]. The metabolite's constituent group is the $\mathrm{C}=0$ amide functional group, which vibrates in the wavenumber of $1630-1680 \mathrm{~cm}^{-1}$ [30]. The optimum formula has the $\mathrm{C}=0$ amide group wavenumber of $1678.19 \mathrm{~cm}^{-1}$; therefore, its therapeutic effect did not change.

\section{Analysis of the release kinetics model and mechanism}

DDSolver provides several statistical criteria for evaluating an appropriate dissolution model. The statistical analysis results using several release kinetics models of diltiazem hydrochloride mucoadhesive bilayer buccal film can be seen in table 3 .

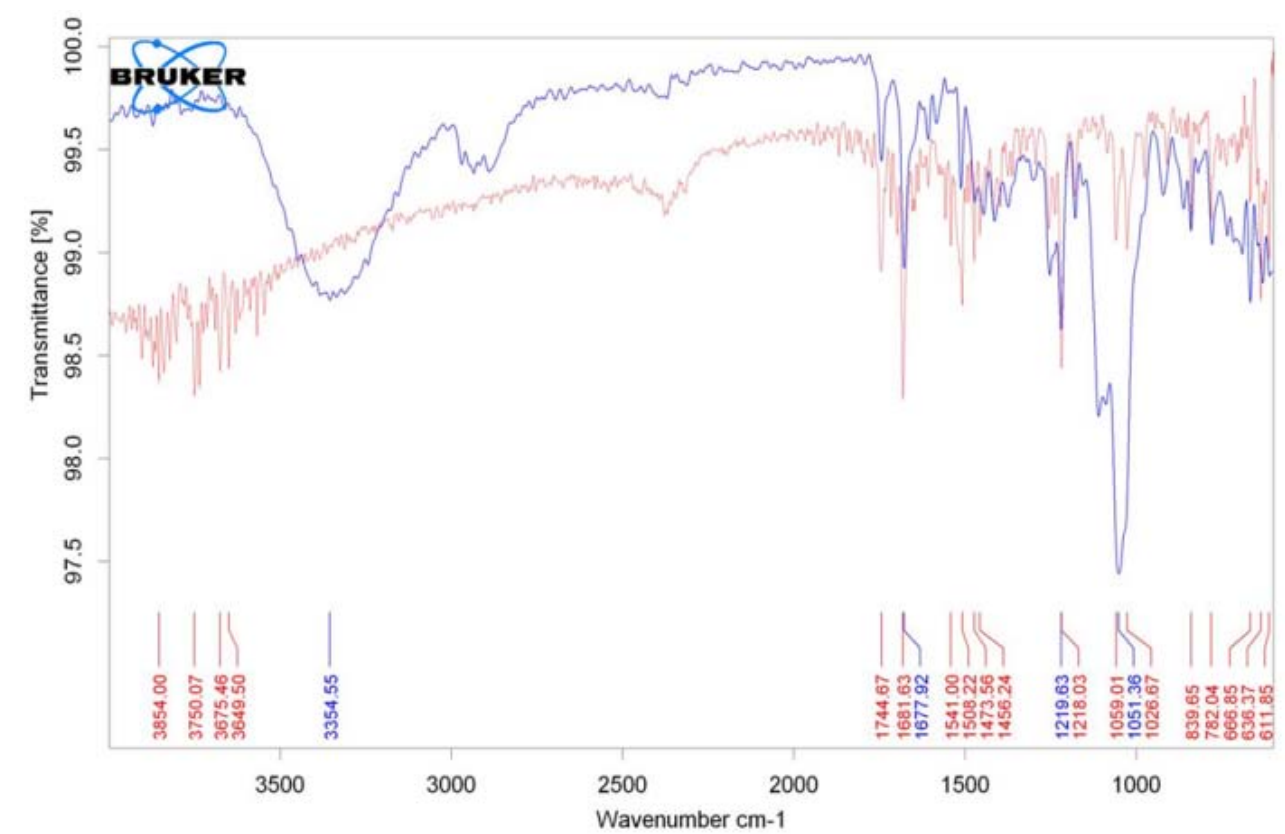

Fig. 2: The overlay of diltiazem hydrochloride (red color) and diltiazem hydrochloride mucoadhesive bilayer buccal film (blue color) FTIR spectra

Table 3: Statistical parameters of diltiazem hydrochloride release kinetics $(n=3)$

\begin{tabular}{|c|c|c|c|c|c|}
\hline Parameters & Zero-order & First-order & Higuchi & Hixson-crowell & Korsmeyer Peppas \\
\hline $\mathrm{R}^{2}$ adjusted & 0.928 & 0.967 & 0.986 & 0.977 & 0.989 \\
\hline AIC & 120.3 & 106.9 & 93.4 & 100.5 & 91.5 \\
\hline MSC & 2.5 & 3.3 & 3.7 & 3.5 & 4.8 \\
\hline MSE & 65.6 & 29.9 & 21.7 & 27.5 & 12.8 \\
\hline WSS & 1048.9 & 478.2 & 375.7 & 428.1 & 110.4 \\
\hline
\end{tabular}

The kinetics model analysis using DD Solver was determined based on the highest value of R2 adjusted and Model Selection Criterion parameters (MSC) and the smallest Akaike Information Criterion (AIC), mean square error MSE and the weighted sum of squares (WWS) parameters. The highest R2 adjusted and MSC indicate the best release kinetics model, and the smallest AIC, MSE, and WWS parameters showed a more precise release kinetics model [31]. The release kinetics model analyzes using DD Solver program follow Korsmesyer Peppas models with a value of R2 adjusted is 0.989 (table 3 ). This result is supported by the curve fitting of the predictive and observative Diltiazem hydrochloride release profile. The Korsmeyer Peppas model shows the smallest difference between Qo and Qc (fig. 3).

The distribution of experimental data (Qo) is around the predicted dissolution data curve $(\mathrm{Qc})$. The dissolution modeling with zeroorder, first-order, Higuchi, and Hixson-Crowell resulted in a larger difference between Qo and Qc [32]. The $\mathrm{n}$ value (release exponent) is 0.624 , indicates that the release follows a non-Fickian diffusion mechanism. Non-Fickian diffusion is the release of drug through polymer diffusion and erosion (relaxation) processes. When the polymer erodes, the drugs could exit from the matrix [33].

HPMC polymer is water-soluble so that the drug diffuses from the expand of the polymer, which forms a gel layer [34]. The AB formula has a high amount of HPMC polymer so that it can absorb more water to undergoes wetting (swelling). The more the swelling will increase drug diffusion. Chitosan has erosive properties due to its low water solubility. From the eroded matrix, the drug can easily be released and dissolved [23]. The release kinetics of Ranitidine hydrochloride from the buccal film containing Sterculia foetida gum and Carbopol 934P also follows the Peppas release kinetics model by diffusion mechanism following non-Fickian transport [35]. Duloxetine hydrochloride follows the zero-order and Higuchi release kinetics when formulated into a buccal film using the combination of HPMC E 15 (hydrophilic polymer) and Eudragit RL 100 (hydrophobic polymer). A combination of hydrophilic, low viscosity 
polymer with a hydrophobic polymer may retard the drug release; therefore, the film's release follows the diffusion-controlled mechanism [36]. This result shows that polymers used for film preparation influence the release kinetics model of drugs.
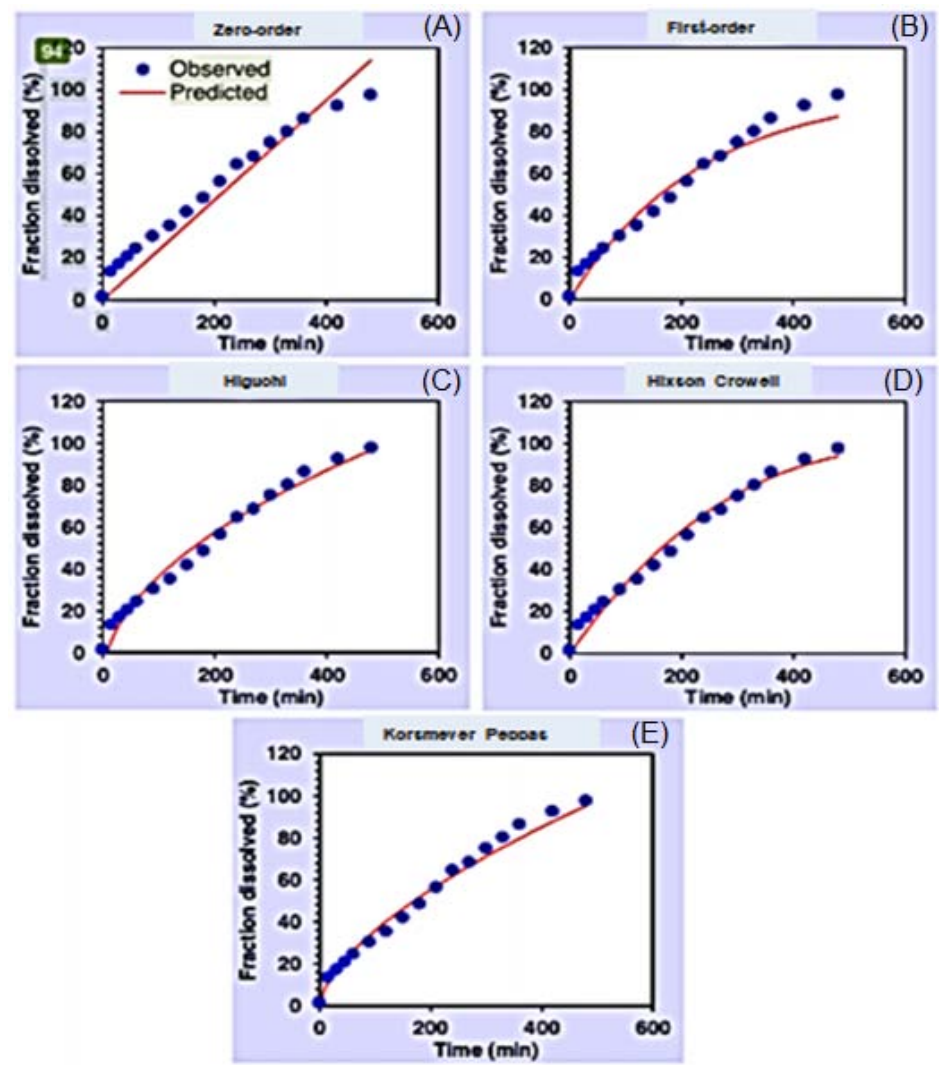

Fig. 3: Diltiazem hydrochloride profile of predictive dissolution $(Q p)$ and observative results $(Q 0)$ versus time $(n=3)$. (A) Zero-order; (B) First-order; (C) Higuchi; (D) Hisxon-Crowell; (E) Korsmeyer peppas

SEM analysis (fig. 4) shows the morphology of the film on the top and bottom surfaces. Smooth top and bottom surface increased comfort during use. The cross-sectional surface at a magnification of 40 times and 100 times shows that the film consists of two-layer, the backing layer, and the mucoadhesive layer. The backing layer reduces the drug's loss by salivary fluid in the mouth and prevents drugs from entering the digestive tract.
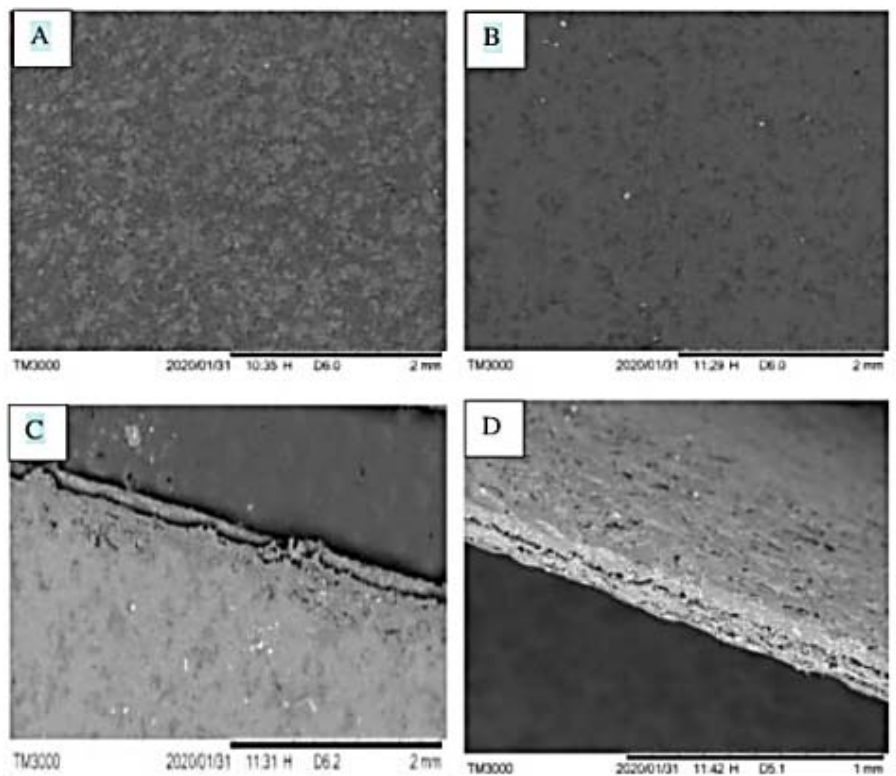

Fig. 4: SEM's image of the buccal film, (A) The upper surface by 300 times magnification; (B) Under surface with 300 times magnification; (C) Film's cross-section with a magnification of 40 times; (D) Film's cross-section with a magnification of 100 times 


\section{CONCLUSION}

Based on the research, the amount of HPMC polymer and chitosan affects the buccal mucoadhesive physical characteristic. Combining HPMC and chitosan could increase the mucoadhesive strength of the buccal mucoadhesive film and its residence time. The optimum formula produces by a combination of HPMC: chitosan $(30 \mathrm{mg}: 10 \mathrm{mg}$ ) based on three optimized responses, a swelling index, mucoadhesive strength, and mucoadhesive residence time. In vitro release study of the optimum formula showed the release kinetics of Diltiazem hydrochloride from the buccal mucoadhesive film following the Korsmeyer Peppas by a non-Fickian diffusion mechanism.

\section{ACKNOWLEDGMENT}

Acknowledgments to the University of Jember for funding this research through the 2019 Keris Batch 1 Grant no. 6701/ UN25/lT/2019.

\section{FUNDING}

Funding from the University of Jember

\section{AUTHORS CONTRIBUTIONS}

All authors have contributed equally.

\section{CONFLICT OF INTERESTS}

Declared none

\section{REFERENCES}

1. DiPiro JT. Pharmacotherapy Handbook Ninth Edition. New York: McGraw-Hill Education; 2015.

2. Sweetman SC. Martindale the complete drug reference. ThirtySixth Edition. London: Pharmaceutical Press; 2009.

3. Patel PS, Parmar AM, Doshi NS, Patel HV, Patel RR, Nayee C. Buccal drug delivery system: a review. Int J Drug Del Res 2013;5:35-48.

4. Khan SV, Trivedi, Boateng J. Functional Physico-chemical, ex vivo permeation and cell viability characterization of omeprazole loaded buccal films for paediatric drug delivery. Int J Pharm 2016;500:217-26.

5. Singh AUK, Sharma, Prajapati SK. A review on mucoadhesive buccal patches. Int J Res Dev Pharm Life Sci 2017;6:2654-60.

6. Mujariya R. A review on study of buccal drug delivery system a review on study of buccal drug delivery system. ISDE 2014;2:2-14.

7. Pawar HA, Surekha JM, Pravin JT, Geevarghese R. Development and evaluation of mucoadhesive patch using a natural polysaccharide isolated from Cordia dichotoma fruit. J Mol Pharm Org Process Res 2014;2:1-6.

8. Morales JO, Mcconville JT. European journal of pharmaceutics and biopharmaceutics manufacture and characterization of mucoadhesive buccal films. Eur J Pharm Biopharm 2011;77:187-99.

9. Mukherjee D, Bharath S. Comparative evaluation of risedronate sodium mucoadhesive films using different mucoadhesive. World J Pharm Pharm Sci 2015;4:1231-47.

10. Jaipal AMM, Pandey SY, Charde PP, Raut KV, Prasanth, Prasad RG. Effect of HPMC and mannitol on drug release and bioadhesion behavior on buccal discs of buspirone hydrochloride: in vitro and in vivo pharmacokinetic studies. Saudi Pharm J 2014;14:1-35.

11. Krampe RJC, Visser HW, Frijlink J, Breitkreutz HJ, Woerdenbag, Preis $\mathrm{M}$, et al. Expert opinion on drug delivery oromucosal film preparations: points to consider for patient-centricity and manufacturing processes. Expert Opin Drug Delivery 2016; 5247:1-41.

12. Kumria RBE, Al-dhubiab J, Shah, Nair AB. Formulation and evaluation of chitosan-based buccal bioadhesive films of zolmitriptan. J Pharm Innov 2018;13:133-43.

13. Averineni RKSG, Sunderajan, Mutalik S, Nayak U, Shavi G, Armugam K, et al. Development of mucoadhesive buccal films for the treatment of oral sub-mucous fibrosis: a preliminary study. Pharm Dev Technol 2009;14:199-207.
14. Zhang YM, Huo J, Zhou A, Zou W, Li C, Yao, et al. DDSolver: an add-in program for modeling and comparison of drug dissolution profiles. AAPS 2010;12:263-71.

15. Murtaza G, Ahmad M, Khan SA, Hussain I. Evaluation of cefixime-loaded chitosan microspheres: analysis of dissolution data using DDsolver. Dissolut Technol 2012;19:13-9.

16. Vaishali K, Nidhi S, Anwar D, Shruti H, Tushar G. Development of stable nanosuspension loaded oral films of glimepiride with improved bioavailability. Int J Appl Pharm 2017;9:28-33.

17. Zainab A, Sadeq, Nawal AR. Studying the effect of different variables on the formulation of mucoadhesive buccal patches of captopril. Int J Appl Pharm 2017;9:16-21.

18. Li W, He W, Gao P, Zhang C, Cai H, Chen Y. Preparation, in vitro and in vivo evaluations of compound calculus Bovis sativus and ornidazole film. Biol Pharm Bull 2016;39:1588-95.

19. Patel A, Shah D. Mucoadhesive buccal films based on chitosan and carboxymethylated Feronia limonia fruit pulp mucilage interpolymer complex for delivery of opioid analgesics. Asian J Pharm 2016;10:2-4.

20. Vergote GJ, Vervaet C, Remon JP, Haemers T, Verpoort F. Nearinfrared FT-Raman spectroscopy as a rapid analytical tool for the determination of diltiazem hydrochloride in tablets. Eur J Pharm Sci 2002;16:63-7.

21. Tejada GM, Barrera G, Piccirilli GN, Sortino M, Frattini A, Salomón CG. Development and evaluation of buccal films based on chitosan for the potential treatment of oral candidiasis. AAPS PharmSciTech 2017;24:1-11.

22. Skulason SMS, Asgeirsdottir JP, Magnusson, Kristmundsdottir T. Evaluation of polymeric films for buccal drug delivery. Pharmazie 2009;64:197-201.

23. Patel VMB, Prajapati G, Patel MM. Design and characterization of chitosan-containing mucoadhesive buccal patches of propranolol hydrochloride. Acta Pharm 2007;57:61-72.

24. Kataria U, Jain C. Buccal films: design and in vitro characterization. Pharm Chem J 2015;2:16-26.

25. Dixit RP, Puthli SP. Oral strip technology: overview and future potential. J Controlled Release 2009;139:94-107.

26. Kathpalia HB, Sule A, Gupte H, Kathpalia B, Sule AG. Development and evaluation of orally disintegrating film of tramadol hydrochloride. Asian J Biomed Pharm Sci 2013;3:27-32.

27. Ghosal KS, Chakrabarty, Nanda A. Hydroxypropyl methylcellulose in drug delivery. Der Pharm Sin 2011;2:15268.

28. Salamat N, Chittchang $M$, Johnston TP. The use of mucoadhesive polymers in buccal drug delivery. Adv Drug Delivery Rev 2005;57:1666-91.

29. Mohamed MI, Haider M, Ali MAM. Buccal mucoadhesive films containing antihypertensive drug: in vitro/in vivo evaluation. J Chem Pharm Res 2011;3:665-86.

30. Shah KUG, Khan M, Wahab A. Diltiazem hydrochloride microcapsules using ethyl cellulose ether derivative polymer as release retarding agent: in vitro chapter. Int $\mathrm{J}$ Res Granthaalayah 2015;3:78-93.

31. Zhang Y, Huo M, Zhou J, Zou A, Li W, Yao C, et al. DDSolver: an add-in program for modeling and comparison of drug dissolution profiles. AAPS J 2010;12:263-71.

32. Nugroho AK, Binnarjo A, Hakim AR, Ermawati Y. Compartmental modeling approach of Losartan transdermal transport in vitro. Indonesian J Pharm 2014;25:31-8.

33. Widiyastuti L, Nugroho AK. The release profile of granule consists of a combination of purifying extract of Centella asiatica and Andrographis paniculata. JFIKI 2016;3:58-61.

34. Iskandarsyah, Sutrio, Hayati D. Hydroxypropyl methylcelluloserelease profile of theophylline controlled-release tablets. MIK 2010;3:58-70.

35. Dixit GR, Chavhan JI, Kanchan, Upadhye P, Misra S. Formulation and characterization of mucoadhesive buccal film of ranitidine hydrochloride using Sterculia Foetida gum as polymer. Asian J Pharm Clin Res 2015;8:68-71.

36. Peddapalli $\mathrm{H}$, Chinnala KM, Banala N. Design and in vitro characterization of mucoadhesive buccal patches of duloxetine hydrochloride. Int J Pharm Pharm Sci 2017;9:52. 